Research Article

\title{
A prospective observational study to compare efficacy and safety of methyldopa and nifedipine in management of moderate gestation hypertension
}

\author{
Anand R. Kanaki, Nitin S. Kunnoor, Sharanabasappa*
}

Department of Pharmacology, MR Medical College, Kalaburagi, Karnataka, India

Received: 12 July 2016 Accepted: 09 August 2016

*Correspondence to:

Dr. Sharanabasappa,

Email: sharan2014@gmail.com

Copyright: (C) the author(s), publisher and licensee Medip Academy. This is an openaccess article distributed under the terms of the Creative Commons Attribution NonCommercial License, which permits unrestricted noncommercial use, distribution, and reproduction in any medium, provided the original work is properly cited.

\begin{abstract}
Background: Hypertensive disorder in pregnancy is one of the most common complications of pregnancy worldwide. It is associated with maternal mortality and morbidity as well as perinatal mortality. Antihypertensive drugs are often used to lower blood pressure with the aim of preventing its progression to adverse outcomes for the mother and the fetus. The risk of developing severe hypertension is reduced to half by using antihypertensive medications. Studies have been done using various antihypertensive in hypertensive disorders of pregnancy. But there are very few studied comparing nifedipine and methyldopa in hypertensive disorders of pregnancy where majority of the studies are evaluated for short duration. Hence we have undertaken this study to compare the efficacy and safety of methyldopa and nifedipine in patient with moderate gestational hypertension.

Methods: This is a prospective observational study where pregnant patients with moderate gestational hypertension either on oral nifedipine $10 \mathrm{mg}$ t.i.d. or on methyl-dopa $250 \mathrm{mg}$ t.i.d. were enrolled during 6 month period. Data at week one and week four were observed along with side effects. Reduction in systolic and diastolic blood pressure from baseline and occurrence of side effects were studied. The statistical significance was at $\mathrm{P}<0.05$.

Results: The mean reduction of systolic/diastolic BP with methyldopa in four weeks was $17 / 13 \mathrm{mmHg}$ as compared to nifedipine being 18.5/14.5 in four week. There was significant reduction in systolic blood pressure in nifedipine group compared to methyldopa group at four weeks (p-0.04). Both treatments were well tolerated with minimal side effects.

Conclusions: Methyldopa and Nifedipine are equally effective in controlling blood pressure in moderate gestational hypertension with minimal side effects. However, nifedipine can be preferred over methyldopa as it showed significant reduction in systolic blood pressure at four weeks.
\end{abstract}

Keywords: Moderate gestational hypertension, Methyldopa, Nifedipine

\section{INTRODUCTION}

In pregnancy until 22-24 weeks, there is a fall in blood pressure caused by active vasodilatation achieved through the action of local mediators such as prostacyclin and nitric oxide. After this, there is a gradual increase in blood pressure until term when pre-pregnancy levels are attained. ${ }^{1}$

The prevalence of hypertensive disorder in pregnancy varies according to geographic regions of world and ranges from $1.5 \%$ in Sweden's to $7.5 \%$ in Brazil. ${ }^{2}$
Hypertensive disorders of pregnancy are common in developing countries like India where it complicate approximately $10 \%$ of pregnancies. ${ }^{3}$ They are important causes of maternal and fetal morbidity and mortality. ${ }^{4}$ Young primigravidae under 20 years and all patients over 30 years have an increased chance of gestational hypertension. $^{5}$

There is no consensus about the definition of hypertensive disorders during pregnancy and several classifications have been suggested. ${ }^{6-8}$ Nevertheless, there is now general agreement about the broad categories. 
Hypertensive disorders of pregnancy are classified into 4 categories: chronic hypertension, preeclampsiaeclampsia, Preeclampsia superimposed on chronic hypertension and Gestational hypertension (transient hypertension of pregnancy or chronic hypertension identified in the latter half of pregnancy). ${ }^{9}$

According to NICE guidelines, in pregnancy mild hypertension means diastolic blood pressure 90-99 $\mathrm{mmHg}$, systolic blood pressure 140-149 $\mathrm{mmHg}$. Moderate hypertension means diastolic blood pressure 100-109 mmHg, systolic blood pressure150-159 mmHg. And severe hypertension means diastolic blood pressure $110 \mathrm{mmHg}$ or greater, systolic blood pressure $160 \mathrm{mmHg}$ or greater. Antihypertensive treatment is not needed in mild hypertension but need to given in all cases of moderate to severe hypertension. ${ }^{9}$

In a multicentre study, approximately $30 \%$ of hypertensive disorders of pregnancy were due to chronic hypertension while $70 \%$ of the cases were diagnosed as gestational hypertension/preeclampsia. ${ }^{3}$

Hypertension in pregnancy will predispose to acute or chronic utero-placental insufficiency that may lead to fetal death, intrauterine growth retardation (IUGR) and preterm delivery. ${ }^{10,11}$ It is proven that control of hypertension reduces these complications. ${ }^{12}$ The commonly used antihypertensive drugs in pregnancy are nifedipine, methyldopa, labetolol and hydralazine. ${ }^{13}$

Methyldopa has been used extensively and appears to be effective and safe both for mother and fetus. ${ }^{14,15}$ Methyldopa is a centrally acting antihypertensive agent. It is a pro drug that exerts its antihypertensive action via an active metabolite. ${ }^{16}$ Maternal side effects include lethargy, drowsiness and depression, and drug-induced hepatitis.

Redman CW, Beilin LJ, Bonnar $\mathrm{J}$ et al showed that hypotensive effect of methyldopa in pregnancy was similar to its action in non-pregnant individuals and greatly reduced the frequency of severe hypertension occurring antenatally and in labour. No serious side effects were encountered. ${ }^{14}$

Marked fall of both systolic and diastolic pressure generally between 24 and 48 hours from the start of using methyldopa was noticed by S. F. Hans et al. ${ }^{17}$

Subhedar V et al showed that treatment of hypertension in pregnancy with methyldopa will reduce Mean Arterial Pressure. $^{18}$

Nifedipine a type 2 calcium channel blocker inhibits the inward flow of calcium across the L-type slow channels of cellular membranes and used as antihypertensive treatment in pregnancy since years, proved its efficacy in treatment of high blood pressure along with safety to mother and fetus. ${ }^{19}$
Nifedipine has been shown to cause relaxation of the uterine smooth muscle and hence its use as a tocolytic agent. In vitro studies have shown the ability of nifedipine to inhibit myometrial contraction in pregnant and non-pregnant women. ${ }^{20}$

Sibai et al. compared bed rest with oral nifedipine in 200 women with pre-eclampsia between 26 and 36 weeks of gestation. They showed a significant reduction in the systolic and diastolic blood pressures with nifedipine, as well as reduction in the number of deliveries for severe hypertension. $^{21}$

Study conducted by Bharathi $\mathrm{K} N$ et al showed rapid fall in systolic blood pressure at 6 hours in both methyl dopa and nifedipine groups and continued to be in normal range till 72 hours but was significant with only in nifedipine group $(\mathrm{p}<0.01) .^{22}$

A prospective clinical trial conducted by Jayawardana $\mathrm{J}$, Lekamge N. et al Srilanka in 126 preganant hypertensive patients showed that nifedipine 30 to $90 \mathrm{mg} / \mathrm{day}$ and methyldopa 750 to $2000 \mathrm{mg} /$ day had average systolic blood pressure of 148 and $152 \mathrm{mmHg}$ respectively during pregnancy, average diastolic blood pressure 102 and 104 mmHg respectively. ${ }^{23}$

Both methyldopa and nifedipine may cause intra uterine growth retardation by producing systemic hypotension- a harmful effect that may compromise feto placental blood flow. ${ }^{24}$ Other side effects include headache, palpitation and insomnia.

Studies have been done using various anti-hypertensives in hypertensive disorders of pregnancy. But there are very few studied comparing nifedipine and methyldopa in hypertensive disorders of pregnancy where majority of the studies are evaluated for short duration. Hence we have undertaken this study to compare the efficacy and safety of methyldopa and nifedipine in patient with moderate gestational hypertension.

\section{METHODS}

This is a prospective observational study conducted at Basavershwara Teaching and General Hospital attached to M.R. Medical College, Kalaburagi. Ethical clearance was obtained from Ethics committee, M.R. Medical College, Kalaburagi. Study was conducted according to Good Clinical Practice.

\section{Inclusion criteria}

All pregnant patients with more than 20 weeks of gestation diagnosed to have moderate gestational hypertension attending obstetrics and gynecology (OBG) department at Basavershwara Teaching and General Hospital between $1^{\text {st }}$ July 2015 to $31^{\text {st }}$ December 2015 were included in the study. Written consent was taken before enrolment. 


\section{Exclusion criteria}

- Hypertensive disorder in pregnancy with preeclampsia/eclampsia.

- Heart diseases including Ischemic Heart Disease, Rheumatic Heart Disease, Dilated cardiomyopathy.

- Haematological disorders, renal disorders and hepatic diseases.

- History of intolerance/hypersensitive to methyldopa/nifedipine.

- Patient with less than 20 week and more than 36 week gestation.

- $\quad$ Patient not willing to give consent.

- $\mathrm{K} / \mathrm{c} / \mathrm{o}$ hypertensive disorder in pregnancy already on antihypertensives.

\section{Procedure}

Moderate gestation hypertension is defined as sitting systolic blood pressure of 150 to $159 \mathrm{~mm}$ of $\mathrm{Hg}$ and a diastolic blood pressure of 100 to $109 \mathrm{~mm}$ of $\mathrm{Hg}$ on two occasions four hours apart after 20 weeks of gestation as per National Institute for Health and Clinical Excellence (NICE) 2011 revised guidelines for the management of hypertensive disorders of pregnancy. ${ }^{9}$

The blood pressure was measured using the validated Mercury sphygmomanometer in sitting position and observed for the appearance and disappearance of Korotk off sounds on two occasions at least 4 hours apart. On each occasion the mean of two readings taken one minute apart after the patient had been resting state for 10 minutes.

\section{Data collection}

All pregnant patients with moderate gestational hypertension either on oral nifedipine $10 \mathrm{mg}$ t.i.d. or on methyl-dopa $250 \mathrm{mg}$ t.i.d. 6 month during study period were included in the study based on inclusion and exclusion criteria. These patients were further categorized in two groups based on antihypertensive (Methyl dopa/nifedipine) given. Nifedipine group consists of 53 patients. Methyl-dopa group consist of 52 patients. Data was collected using standard case record form. All outpatients were seen at week one and at week four after starting treatment. Side effects of the drugs were also recorded during study period.

The primary outcome was mean reduction in Systolic Blood Pressure and Diastolic Blood Pressure without using additional drugs at week 4 . Secondary outcomes included maternal side effects such as hypotension, maternal tachycardia, headache, flushing, nausea and vomiting, dizziness or cardiovascular accidents after starting the antihypertensive medication.

\section{Statistical analysis}

Descriptive data was presented as mean with standard deviation (SD). Two tailed ' $t$ ' test was used to compare reduction in systolic and diastolic blood pressure in one week and four weeks with respect to baseline between two groups. The Statistical Package for the Social Sciences (SPSS) version 20.0 software (SPSS Inc, Chicago, IL, USA) was used for statistical analysis. A p value of $<0.05$ was considered statistically significant.

\section{RESULTS}

A total of 105 pregnant patients with moderate gestational hypertension were enrolled in the study during 6 month period ( $1^{\text {st } J u l y ~} 2015$ to $31^{\text {st }}$ December 2015). 10 patients, 4 in methyldopa and 6 in nifedipine group didn't comply with the follow up and were excluded from the analysis. We present analysis of 95 patients who completed the study.

The demographic and clinical characteristics of the two groups at the time of enrolments Tablet 1.In the present study, about $17(35.4 \%)$ of the pregnant women in methyldopa group and $18(38.3 \%)$ in nifedipine group were primigravidae (Table 1).

Table 1: Clinical characteristics of study population.

\begin{tabular}{|c|c|c|c|c|}
\hline Characters & Group & $\mathbf{n}$ & Mean \pm SD & $\begin{array}{l}\text { p- } \\
\text { value }\end{array}$ \\
\hline \multirow{2}{*}{ Age (years) } & Methyl dopa & 48 & $25.6 \pm 1.84$ & \multirow{2}{*}{0.60} \\
\hline & Nifedipine & 47 & $25.8 \pm 1.97$ & \\
\hline \multirow{2}{*}{$\begin{array}{l}\text { Weight } \\
\text { (kg) }\end{array}$} & Methyl dopa & 48 & $55.6 \pm 2.28$ & \multirow{2}{*}{0.64} \\
\hline & Nifedipine & 47 & $55.3 \pm 2.31$ & \\
\hline \multirow{2}{*}{$\begin{array}{l}\text { Gestational } \\
\text { age at } \\
\text { enrolment } \\
\text { (weeks) }\end{array}$} & Methyl dopa & 48 & $27.6 \pm 2.43$ & \multirow[b]{2}{*}{0.69} \\
\hline & Nifedipine & 47 & $27.4 \pm 2.42$ & \\
\hline \multirow{2}{*}{$\begin{array}{l}\text { Initial } \\
\text { systolic } \\
\text { blood } \\
\text { pressure } \\
(\mathrm{mm} \mathrm{Hg})\end{array}$} & Methyl dopa & 48 & $153.6 \pm 3.14$ & \multirow[b]{2}{*}{0.62} \\
\hline & Nifedipine & 47 & $153.2 \pm 3.57$ & \\
\hline \multirow{2}{*}{$\begin{array}{l}\text { Initial } \\
\text { diastolic } \\
\text { blood } \\
\text { pressure } \\
\text { (mm Hg) }\end{array}$} & Methyl dopa & 48 & $102.6 \pm 3.43$ & \multirow[b]{2}{*}{0.08} \\
\hline & Nifedipine & 47 & $103.8 \pm 3.51$ & \\
\hline
\end{tabular}

In the present study, the mean systolic blood pressure in patients treated with methyldopa on admission was 153.6 $\mathrm{mmHg}$, while in one week it reduced to $143.7 \mathrm{mmHg}$ and in four weeks it reduced to $136.2 \mathrm{mmHg}$. With nifedipine the mean systolic blood pressure on admission was 153.2 $\mathrm{mmHg}$ which reduced to $142.5 \mathrm{mmHg}$ in one week and to 134.5 in four weeks. 
Similarly, the mean diastolic blood pressure in patients treated with methyldopa on admission was $102.6 \mathrm{mmHg}$, while in one week it reduced to $96.3 \mathrm{mmHg}$ and in four week it reduced to $89.4 \mathrm{mmHg}$. With nifedipine the mean diastolic blood pressure on admission was $103.9 \mathrm{mmHg}$ which reduced to $96.1 \mathrm{mmHg}$ in one week and to 89.2 in four weeks (Table 2).

Table 2: Comparison of blood pressure control among the two groups.

\begin{tabular}{|c|c|c|c|c|c|c|}
\hline Parameters & Drugs & Baseline & One week & $\mathbf{P}$ & Four week & $\mathbf{p}$ \\
\hline \multirow{2}{*}{ Systolic BP } & Methyl dopa & $153.6 \pm 3.1$ & $143.7 \pm 3.5$ & \multirow{2}{*}{0.11} & $136.2 \pm 3.5$ & \multirow{2}{*}{0.04} \\
\hline & Nifedipine & $153.2 \pm 3.5$ & $142.5 \pm 3.9$ & & $134.5 \pm 4.5$ & \\
\hline \multirow{2}{*}{ Diastolic BP } & Methyl dopa & $102.6 \pm 3.43$ & $96.3 \pm 3.5$ & \multirow{2}{*}{0.78} & $89.4 \pm 3.4$ & \multirow{2}{*}{0.78} \\
\hline & Nifedipine & $103.9 \pm 3.51$ & $96.1 \pm 3.7$ & & $89.2 \pm 3.7$ & \\
\hline
\end{tabular}

The methyldopa group shown mean systolic blood pressure reduction of $10 \mathrm{mmHg}$ by one week and 17 $\mathrm{mmHg}$ by four weeks as compared to nifedipine group which shown reduction of $10.5 \mathrm{mmHg}$ in one week and $18.5 \mathrm{mmHg}$ in four weeks. There was significant reduction in systolic blood pressure in nifedipine group compared to methyldopa group in four weeks (p-0.04) (Table 2).

The methyldopa group shown mean diastolic blood pressure reduction of $6 \mathrm{mmHg}$ by one week and 13 $\mathrm{mmHg}$ by four weeks as compared to nifedipine group which shown reduction of $7.5 \mathrm{mmHg}$ in one week followed by reduction of $14.5 \mathrm{mmHg}$ in four weeks. No significant difference between two groups. There were no cases of eclampsia or imminent eclampsia during treatment in either group (Table 2).

The adverse effects of two groups were mild and generally well tolerated; the most common were headache, palpitation and insomnia (Table 3 ).

\section{Table 3: Side effects of Nifedipine and Methyl Dopa group.}

\begin{tabular}{|c|c|c|c|c|}
\hline \multirow{2}{*}{$\begin{array}{l}\text { Side } \\
\text { effects } \\
\text { observed }\end{array}$} & \multicolumn{2}{|c|}{$\begin{array}{l}\text { Methyl dopa } \\
\text { group }(n=48)\end{array}$} & \multicolumn{2}{|c|}{$\begin{array}{l}\text { Nifedepine group } \\
(\mathrm{n}=47)\end{array}$} \\
\hline & $\begin{array}{l}\text { Number of } \\
\text { patients }\end{array}$ & $\%$ & $\begin{array}{l}\text { Number of } \\
\text { patients }\end{array}$ & $\%$ \\
\hline Headache & 13 & $27 \%$ & 22 & $47 \%$ \\
\hline Palpitation & 11 & $23 \%$ & 05 & $11 \%$ \\
\hline Dizziness & 06 & $13 \%$ & 00 & \\
\hline Weakness & 02 & $04 \%$ & 00 & \\
\hline Insomnia & 03 & $06 \%$ & 05 & $11 \%$ \\
\hline
\end{tabular}

\section{DISCUSSION}

We analysed 95 women with gestational hypertension during 6 month study period. Mean age of participants in both groups was 25 years among which one third of them were primigravida. Study conducted by Aparna et al had same age distribution as our study but two third of them were primigravida (Table 1$).^{25}$
The methyldopa group shown mean systolic blood pressure reduction of $10 \mathrm{mmHg}$ in one week and 17 $\mathrm{mmHg}$ in four weeks as compared to nifedipine group which shown reduction of $10.5 \mathrm{mmHg}$ in one week and $18.5 \mathrm{mmHg}$ in four weeks. There was significant reduction in systolic blood pressure in nifedipine group compared to methyldopa group in four weeks (p-0.04) (Table 2).

The methyldopa group shown mean diastolic blood pressure reduction of $6 \mathrm{mmHg}$ in one week and 13 $\mathrm{mmHg}$ in four weeks as compared to nifedipine group which shown reduction of $7.5 \mathrm{mmHg}$ in one week followed by reduction of $14.5 \mathrm{mmHg}$ in four weeks. No significant difference between two groups (Table 2).

Redman CW, Beilin LJ et al showed that methyldopa did control moderate hypertension in 242 pregnant women with no serious side effects. ${ }^{14}$

Subhedar V et al compared methyldopa $250 \mathrm{mg}$ tid and labetalol $100 \mathrm{mg}$ tid in 180 patients with PIH in South India showed fall of mean arterial pressure from 109.86 $\mathrm{mmHg}$ to $98.15 \mathrm{mmHg}$ at 7 day of methyl dopa administration with a statistically significant $\mathrm{p}$ value $<0.05$ and with labetalol, fall of mean arterial pressure from $109.48 \mathrm{mmHg}$ to $96.90 \mathrm{mmHg}$ at 7 day. ${ }^{18}$

Sibai et al. showed significant reduction in the systolic ( $\mathrm{p}$ $<0.0001$ ) and diastolic blood pressure ( $\mathrm{p}<0.0001)$ with oral nifedipine in 200 women with pre-eclampsia between 26 and 36 weeks of gestation. ${ }^{21}$

Whereas study conducted by Bharathi $\mathrm{K} \mathrm{N}$ et al at South India in 50 patients showed both nifedipine (systolic blood pressure reduction from $160 \mathrm{mmHg}$ to $139 \mathrm{mmHg}$, diastolic blood pressure from $105 \mathrm{mmHg}$ to $91 \mathrm{mmHg}$ ) and methyldopa (systolic blood pressure reduction from $156 \mathrm{mmHg}$ to $138 \mathrm{mmHg}$, diastolic blood pressure from $105 \mathrm{mmHg}$ to $92 \mathrm{mmHg}$ ) are equally effective in reducing the blood pressure in pregnancy induced hypertension at 72 hours. $^{22}$ 
Adverse effects in our study were mild, well tolerated and similar in both groups. They include headache, palpitation and insomnia. Adverse effects profile was similar to study conducted by Subhedar V et al and ElQarmalawi et al (Table 3). ${ }^{18,26}$

Our study reported the effectiveness of methyldopa and nifedipine among 95 patients with moderate gestational hypertension with a follow up of four weeks. Nifedipine having an additional tocolytic action showed significant reduction of systolic blood pressure at one month compared to methyldopa.

This was single centre study and patients were followed up only for four weeks and patient with moderate gestational hypertension already on antihypertensive are not included in study. Further study is needed to evaluate effectiveness of these drugs in large sample size for longer period during pregnancy.

Monotherapy with either methyldopa or nifedipine could be used safely in pregnant patients with moderate gestational hypertension. However, nifedipine is slightly better compared to methyldopa because it showed significant reduction systolic blood pressure at one month with minimal side effects.

\section{ACKNOWLEDGEMENTS}

The authors thank the Department of OBG for their assistance during study. Special memorable thanks to staffs, colleagues of Pharmacology Department \& Dr. Bindu Shree for their encouragement, guidance and for providing the necessary facilities for carrying out this research.

Funding: No funding sources

Conflict of interest: None declared

Ethical approval: The study was approved by the Institutional Ethics Committee

\section{REFERENCES}

1. API India Medicine Update. Managing hypertension in pregnancy. 2012. Available at http://www.apiindia.org/pdf/medicine_update_2012/ hypertension_08.pdf.

2. Datta D, Concessao LP. Management of Hypertension in Pregnancy. Journal of Pharmacy research. 2011;4(5):1340-2.

3. Report of the National High Blood Pressure Education Program Working Group on High Blood Pressure in Pregnancy. Am J Obstet Gynecol. 2000;183(1):S1-22.

4. Chauhan R, Sharma RS, Parashar MK, Chauhan VS. Clinical examination of hypertension in pregnancy. In: Shah MR, editor. Hypertensive disorders in pregnancy: 1st ed. New Delhi: Jaypee Brothers Medical Publishers (P) Ltd. 2007:111-25.
5. Zibaeenazhad MJ, M Ghodsi P Arab, Gholzom N. The prevalence of hypertensive disorders of pregnancy in Shiraz, Southern Iran; Iranian Cardiovascular Research Journal. 2010;4:169-72.

6. Davey DA, Mac Gillivray I. The classification and definition of the hypertensive disorders of pregnancy. American Journal of Obstetrics and Gynecology. 1988;158:892-8.

7. Gifford RW, August P, Chesley LC, Cunningham G, Ferris TF, Lindheimer MD. National high blood pressure education program working group report on high blood pressure in pregnancy. American Journal of Obstetrics and Gynecology. 1990;163:1691-712.

8. North RA, Taylor RS, Schellenberg JC. Evaluation of the definition of pre-eclampsia. British Journal of Obstetrics and Gynaecology. 1999;106:767-73.

9. NICE Guidelines. Hypertension in pregnancy: the management of hypertensive disorders during pregnancy. 2010 (Revised 2011). Available online: www.nice.org.uk.

10. Lindheimer A, Umans JG. Explaining and predicting preeclampsia. New England Journal of Medicine. 2006;355:1056-58.

11. Saudan P, Brown MA, Buddle ML. Does gestational hypertension become pre-eclampisa? British Journal of Obstetrics and Gynecology. 1998;105:1177-84.

12. Leather HM, Humphreys DM, Baker P, Chadd MA. A controlled trial of hypotensive agents in hypertension in pregnancy. Lancet. 1968;2:488-90.

13. Rey E, LeLorier J, Burgess E, Lange IR, Leduc L. Report of the Canadian Hypertension Society Consensus Conference: 3.Pharmacologic treatment of hypertensive disorders in pregnancy. CMAJ. 1997;157(9):1245-54.

14. Redman CWG, Beilin LJ, Bonnar J. Treatment of hypertension in pregnancy with methyldopa: blood pressure control and side effects. British Journal of Obstetrics and Gynaecology. 1977;84:419-26.

15. Redman CWG. Drugs, hypertension and pregnancy. Prog Obstet Gynaecol. 1989:83-95.

16. Thomas M, Hoffman BB. Treatment of myocardial ischemia and Hypertension. In: Laurence L. Brunton, Brunce A. Chabner, Bjorn C. Knollmann, editors. Goodman and Gilman's The pharmacological basis of therapeutics. 12th ed. Mcgraw Hill. 2011;27:773-74.

17. Hans SF, Kopelman H. Methyldopa in treatment of severe toxaemia of pregnancy. British Medical Journal. 1964;1:736-9.

18. Subhedar V, Inamdar S, Hariharan C, Subhedar S. Comparison of efficacy of labetalol and methyldopa in patients with pregnancy-induced hypertension. International Journal of Reproduction, Contraception, Obstetrics and Gynecology. Int J Reprod Contracept Obstet Gynecol. 2013;2(1):2734.

19. Sorkin EM, Clissold SP, Brogden RN. Nifedipine. A review of its pharmacodynamic and pharmacokinetic properties, and therapeutic efficacy 
in ischaemic heart disease, hypertension and related cardiovascular disorders. 1985;30:182-274.

20. Ulmsten U, Anderssn KE, Forman A. Relaxing effects of nifedipine on the pregnant uterus in vitro and in vivo. Relaxing effects of nifedipine on the pregnant uterus in vitro and in vivo. 1978;52:53641.

21. Sibai BM, Barton JR, Sherif AKL, Sarinoglu C, Mercer BM. A randomized prospective comparison of nifedipine and bed rest versus bed rest alone in the management of preeclampsia remote from term. 1992;167:879-84.

22. Bharathi KN, Prasad KVSRG, Jagannath P, Nalini KS. Comparison of Nifedipine with Methyldopa For Control Of Blood Pressure In Mild To Moderate
Pregnancy Induced Hypertension. Journal of clinical and diagnostic research. 2010;4(3):2406-9.

23. Jayawardena J, Lekamge $\mathrm{N}$. A comparison of nifedipine with methyldopa in pregnancy induced hypertension. Ceylon Med J. 1994;39(2):87-90.

24. Fairbanks LD, Escuredo E, Duley JA, Simmonds HA. S. Adv Exp Med Biol 2000;486:383-8.

25. Aparna J. A randomized, double-blind, comparative trial of nifedipine and methyldopa in moderate pregnancy induced hypertension. Der Pharmacia Lettre. 2013:5(4):274-7.

26. El-Qarmalawi AM, Morsy AH, Al-Fadly A, Obeid A, Hashem M. Labetalol vs. methyldopa in the treatment of pregnancy-induced hypertension. Int $\mathrm{J}$ Gynaecol Obstet. 1995;49:125-30.

Cite this article as: Kanaki AR, Kunnoor NS, Sharanabasappa. A prospective observational study to compare efficacy and safety of methyldopa and nifedipine in management of moderate gestation hypertension. Int J Basic Clin Pharmacol 2016;5:2080-5. 